\title{
Using a Problem-Based Learning Approach to Teach an Intelligent Systems Course
}

\author{
France Cheong \\ Royal Melbourne Institute of Technology University \\ Melbourne, Australia
}

france.cheong@rmit.edu.au

An earlier version of this work appeared in the online proceedings of the Computer Science and Information Technology Conference 2007 and is available at http://csited.org/2007/7CheoCSITEd.pdf

\section{Executive Summary}

While delivering the Intelligent Systems course, an elective course in the Master of Business Information Technology program at RMIT University, it was felt that there was a learning issue as students' learning seemed to be superficial. This perception was based on the questions students asked in class and the mechanical attitude they adopted while doing lab work. In the next version of the course, it was decided to trial a problem-based learning (PBL) teaching and learning approach in order to improve students' learning experience.

PBL is a revolutionary and radical teaching approach. It is completely different from the traditional lecture-tutorial approach as there is a shift of power from the "expert teacher" to the "student learner". In the traditional teacher-centered approach, the teacher is knowledgeable in the subject matter and the focus of teaching is on the transmission of knowledge from the expert teacher to the novice student. In contrast, the PBL approach is a student-centered approach in which the focus is on student's learning and what they do to achieve this. In such an environment, the role of the teacher is more of a facilitator than an instructor.

In order to use PBL effectively, it is important to understand how it is grounded in current theories of teaching and learning so that insights from these theories can be applied to refine the practice of PBL. Findings from cognitive psychology suggest that learning is a constructive and not a receptive process. Cognitive processes known as metacognition affect the use of knowledge, and social and contextual factors affect learning. When educating students, explicit attention should be paid to their existing knowledge to provide them a framework for learning. Learning is quicker when students possess self-monitoring skills known as metacognition (i.e. the student's ability to analyze, reflect on, and understand his or her own cognitive and learning processes). Metacognitive skills allow students to monitor their own learning and, contrary to prior beliefs, they can be

Material published as part of this publication, either on-line or in print, is copyrighted by the Informing Science Institute. Permission to make digital or paper copy of part or all of these works for personal or classroom use is granted without fee provided that the copies are not made or distributed for profit or commercial advantage AND that copies 1) bear this notice in full and 2) give the full citation on the first page. It is permissible to abstract these works so long as credit is given. To copy in all other cases or to republish or to post on a server or to redistribute to lists requires specific permission and payment of a fee. Contact Publisher@InformingScience.org to request redistribution permission. taught. Learning must be contextualized in order to be effective and social factors also affect learning since students evolve their problem-solving methods and conceptual knowledge when working in small groups.

When using the PBL approach, it is necessary for students to follow a carefully planned process to guide them through the complex tasks of brainstorming, identifying useful knowledge, formulat- 
ing appropriate research questions, and working out strategies for finding solutions. The PBL process used was adapted from the literature.

When redesigning the course, it was decided to retain the first part of the course as this part operated without major problems. Delivering the whole course using the PBL approach was considered too risky because of a complete shift from one extreme (teacher-centered learning) to another (student-centered learning). Furthermore using a PBL approach in one part of the course would enable comparison with the traditional method used in another part of the course. The redesigned course was offered in semester 1, 2006, and the first part of the course ran smoothly without any apprehension about programming from students (this was a concern in the previous version of the course). Since PBL is a drastic change in learning approach and students are encouraged to be active rather than passive and co-operate rather than compete, they must be prepared for the new approach in order to minimize potentially distressing aspects and maximize learning opportunities. An induction to PBL was offered to students in the first session of the second part of the course.

The PBL approach was evaluated using a questionnaire survey at the end of the course. Although $88 \%$ of students enjoyed the PBL experience, their preferences leaned towards a combined traditional and PBL approach.

Keywords: Problem-based learning, instructivist, constructivist, intelligent systems, expert systems.

\section{Introduction}

Intelligent Systems is an elective course in the Master of Business Information Technology (MBIT) program offered by the School of Business IT of RMIT University. This course has been offered since the early nineties and although its name has evolved from Expert Systems to the trendy name of Intelligent Systems, its contents were essentially centred around Expert Systems. In spring 2004, the course was revamped by retaining and strengthening the Expert Systems part of the course which was covered in the first half of the course and in the second half of the course topics such as fuzzy logic, evolutionary computation, artificial neural networks, Bayesian networks, intelligent agents, etc were included to make the course more in line with its name. Furthermore, given the difficulties previous course coordinators experienced in finding a readily available and up-to-date Expert System shell (VP-Expert was used in the past and is no longer available), it was decided to use the Java Expert System Shell (JESS) for teaching the Expert System part of the course as it is freely-available for teaching purposes.

When the course was delivered in spring 2004, 25 students initially enrolled and this number eventually dropped down as only 16 students completed the course. One of the main reasons students dropped out of the course was that the first lab was a tutorial on how to use JESS and some students perceived the course to be heavily programming-oriented. In the MBIT program, students are taught a blend of business and IT skills and they learn how to manage IT as well as use IT to manage business systems. One of the main reasons students are attracted to the program is to obtain IT-related managerial and business skills rather than IT-related technical skills. Thus, a large proportion of MBIT students are not interested in courses that contain heavy programming components.

While delivering the course, the first half of the course where Expert Systems were covered went quite well despite initial apprehensions about programming. However, in the second half of the course it was felt that students' learning was superficial. This perception is based on the questions they asked and the mechanical attitude they adopted while doing the lab work. No programming was involved in the second part of the course. Student feedback at the end of the course indicated that too many topics were covered. 
In order to address the learning issue, it was decided to not only to reduce the number of topics covered in the course but also use a different approach for teaching the next version of the course. More specifically, it was thought that a constructivist approach such as problem-based learning (PBL) would improve students' learning experience in the course.

\section{PBL Approach to Learning}

PBL is the learning that results from the process of working towards the understanding and resolution of a problem in a real context (Barrows \& Tamblyn, 1980). It is different from the conventional lecture-tutorial approach where students acquire and absorb information from their teachers and use it for solving problems in order to determine their level of comprehension and application of the subject matter. In the PBL approach, students are presented with a situation that leads to a problem for them to solve. Students learn through the act of trying to solve the problem. They analyze the problem, gather information, generate and evaluate possible solutions to find the best one and then present their conclusions. Frequently, the problems have no single right answer.

PBL was first started by Barrows and Tamblyn (1980) at McMaster University, Canada in September 1969 for educating medical students to become physicians. The roots of PBL can be traced to the progressive movement, especially to Dewey's (1944) belief that teaching should appeal to students' natural instincts to investigate and create. Inspired by Dewey's maxim, Howard Barrows, a physician and medical educator at McMaster University developed PBL for educating physicians to foster their own capabilities for reflection outside of school in ordinary life.

PBL began as a revolutionary and radical approach for teaching medical students in the newly created medical school of McMaster University. Subsequently, PBL curricula were established in medical schools in the Netherlands, Australia, and the United States (Barrows, 2000). The new teaching approach also spread to the teaching of non-medical disciplines such as architecture, business, construction, engineering, law, and others. PBL has also been implemented at different educational levels (Wee Keng Neo, 2004): primary school, secondary school, polytechnic, university, professional trade bodies, and continuing education. It has also evolved from small-group learning to large classes and crossed international borders, from Canada and the United States to Asia, Australia, Europe, and the United Kingdom.

Many different practices of PBL have emerged as a result of its rapid growth as variations can be seen in the following areas (Barrows, 2000):

- Curriculum design. The extent to which the curriculum is PBL Is PBL used in all years of study, specific years, part of a subject, a whole subject, etc?

- Problem format. Use of case studies, vignettes, problem scenarios, simple to complex scenarios, etc

- Role of facilitator. The style of the facilitator varies from case-method teaching to facilitation of small groups. The extent to which the facilitator provides information ranges from providing information as a resource list to providing no information at all.

- Group size. The size of the student group varies from a small group of 6 students to a large class of more than 100 students.

- Degree of students' responsibility for their own learning. Varies from teachercontrolled to student controlled.

- Assessment methods. Vary from multiple-choice questions to performance-based assessments.

- Grading. Varies from grades to pass/fail decisions. 
Problem-based learning is sometimes confused with problem-solving learning (Savin-Baden, 2000). Problem-solving learning is the type of learning that has been traditionally used for years. In problem-solving learning, students are given a lecture and then a set of questions based on the information given. Students are expected to find solutions to these questions and bring them to the class for discussion. The focus is largely on finding the answers expected by the lecturer and these answers are rooted in the information supplied to students. PBL is different as the focus here is on organizing curricula around problem scenarios and students are not required to acquire a predetermined series of right answers. Instead they are expected to engage in the complex situation presented to them and decide what information they need to learn and what skills they need to gain in order to solve the problem.

\section{PBL and Educational Theories}

PBL is based on the theory that views learning as a process in which the learner actively constructs knowledge (Gijselaers, 1996). Students solve problems that serve as a stimulus to learning in small groups guided by a tutor whose role is to facilitate the learning process by asking questions and monitoring the process. In order to use PBL effectively, it is important to understand how it is grounded in current theories of teaching and learning so that insights from these theories can be applied to refine the practice of PBL.

A theoretical basis for improving teaching in general and PBL in particular is provided by findings from cognitive psychology. According to Glaser (1991), learning is a constructive and not a receptive process, cognitive processes called metacognition affect the use of knowledge, and social and contextual factors affect learning.

Until twenty or thirty years ago, it was believed that learning involves filling students' heads with information (Bruer, 1993). The aim of teaching was to lead students to store knowledge in memory, and the successful retrieval of information was a function of the effectiveness of the classification of the information. However, according to modern cognitive psychology theories, the most important feature of memory is its associative structure (Bruer, 1993; Brunning, Schraw, \& Ronning, 1995). Knowledge is structured as networks of related concepts known as semantic networks. Learning occurs by associating new information with existing networks and depending on how this is done by learners, the new information can be easily retrieved for problem solving, recognition of situations, or recall of factual knowledge. Therefore, when educating students, explicit attention should be paid to their existing knowledge to provide them a framework for learning. A basic requirement of learning is the activation of existing knowledge to facilitate processing of new information.

A second important principle, according to Bruer (1993), is that learning is quicker when students possess self-monitoring skills known as metacognition (also known as "knowing about knowing" or "thinking about thinking"). Possessing an extensive body of knowledge does not in itself guarantee that a problem will be successfully solved; good use of problem solving methods is also required. Metacognition is the student's ability to analyze, reflect on, and understand his or her own cognitive and learning processes. It involves: goal setting (What should I do?), strategy selection (How do I do it?), and goal evaluation (Did it work?). If students are aware of their cognitive strengths and weaknesses, they can adjust and compensate for them by using the appropriate learning strategies in the right context. Metacognitive skills allow students to monitor their own learning. According to Bruning, Schraw, and Ronning (1995), metacognitive skills are teachable through such strategies as: (a) focusing on understanding (deep learning) rather than surface memory; (b) promoting elaboration of ideas; and (c) demonstrating the types of questions that students should ask themselves during the problem solving process. 
A third important principle for teaching and learning is that learning must be contextualized in order to be effective. There are many cases in the literature which criticize the ineffectiveness of traditional education. For example, students do not have an enhanced understanding of physics problems despite being formally taught physics theories (Clement, 1983). Two models that advocate contextualized learning are: cognitive apprenticeship (Collins, Brown, \& Newman, 1989) and anchored instruction (Bransford, Sherwood, Hasselberg, Kinzer, \& Williams, 1990). These models emphasize the fact that teaching should occur within the context of real-world problems or professional practice. In cognitive apprenticeship, students learn in the context they will work after they graduate, while in apprentice learning students are able to see how experts use subject knowledge and metacognitive skills for solving problems. Thus, when content is linked with context, knowledge is more accessible when confronted with new problems (Schmidt, 1993). Social factors also affect learning (Glaser, 1991) since in small group work students evolve their problem-solving methods and conceptual knowledge. They express different views on the problem and share ideas and responsibilities in managing the situation.

\section{The PBL Process}

Due to the flexibility and freedom offered by PBL, it is necessary for students to follow a carefully planned process if they are to experience success. A process is required to guide the students through the complex tasks of brainstorming, identifying useful knowledge, formulating appropriate research questions, and working out strategies for finding solutions. A carefully planned process avoids blind alleys and builds stable platforms from which students can jump to the next step (Delisle, 1997).

The PBL process shown in Figure 1 consists of at least three major stages (Wee Keng Neo, 2004): first meeting, self-directed learning, and second meeting. In the first meeting, students are presented with the problem, triggering learning. They analyze the problem from their point of view and try to make sense of the problem by engaging their prior knowledge. Reasoning and problem solving activities are performed under the guidance of a facilitator. Students clarify and identify the problem, suggest ideas and determine what they need to know to manage the problem. They formulate an action plan to find, evaluate, synthesize, and apply information needed to solve the problem. Students then break off for their independent self-directed learning activities.
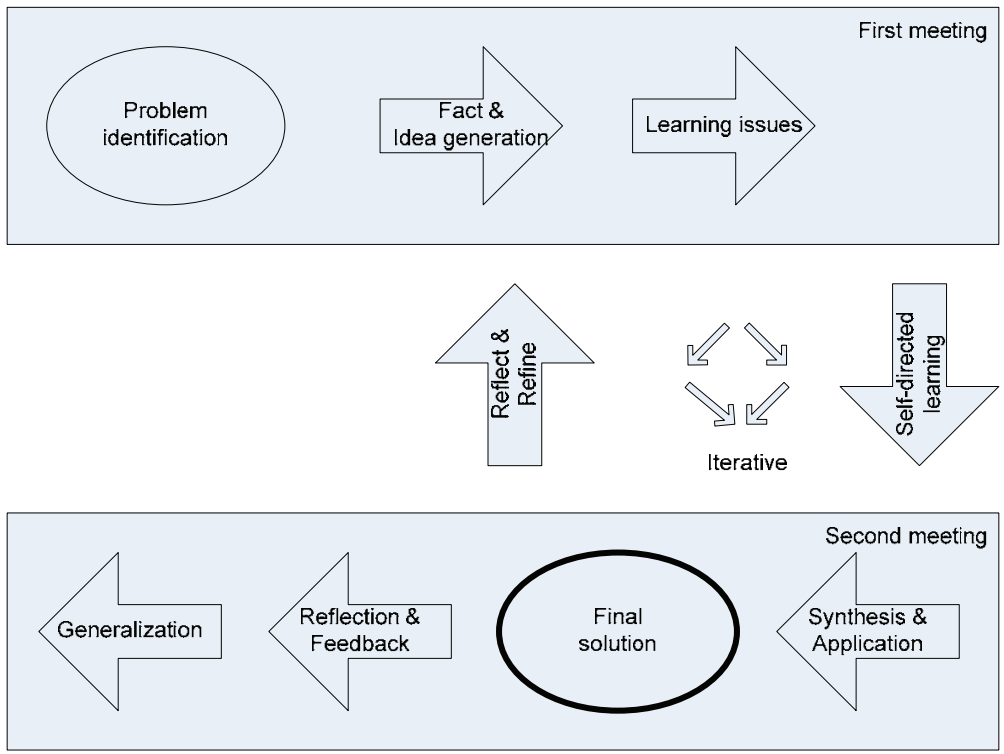

Figure 1: PBL cycle 
In the second meeting, students share and review their information and maybe revise their prior assumptions. The new knowledge acquired may be sufficient to solve the problem, otherwise (especially for more complex problems) the students need to reflect on and refine their learning strategies, engage in more self-directed learning, and reconvene more meetings until the problem is satisfactorily solved.

After the problem is solved, students reflect on how they could improve their learning performance and generalize the solution so that they can apply what they have learned in a similar situation in the future. Students are also required to provide feedback on individual and group performance for assessment and improvement purposes.

\section{Design of the Course}

As previously mentioned, a large proportion of our students are not interested in courses that contain heavy programming components as many of them would have gained these skills in their undergraduate degrees. Thus, the focus of the courses offered within the MBIT program is on teaching students a blend of business and IT skills, and this is one of the main reasons of the popularity of the program.

In the previous version of the Intelligent Systems course, in order to make the course attractive to students, a framework was created that shielded them from most of the LISP-like code required to implement a complete Expert System when using JESS. When using this framework, students only have to write business rules without worrying about code for: defining templates, asking questions, generating outputs, etc. All students need to do is write their identified business rules using the LISP-like notation used by JESS.

When redesigning the course, it was decided to retain the first part of the course as this part operated without major problems. Delivering the whole course using the PBL approach was considered too risky because of a complete shift from one extreme (teacher-centered learning) to another (student-centered learning). Furthermore using a PBL approach in one part of the course would enable comparison with the traditional method used in another part of the course.

The first seven weeks of the course was designed to be delivered as a traditional weekly one-hour lecture followed by a two-hour tutorial and the only change made to that part of the course was the introduction of a set of hurdle tests that students could take online in their own time. The tests were made up of multiple choice questions developed in XML. They were executed and automatically marked through the WebLearn software (developed by the School of Computer Science and Information Technology of RMIT University) hosted within RMIT's Distributed Learning System (DLS) environment which also contains the Blackboard Learning System. The aim of these tests was to motivate students to read the lecture notes and the assigned reading material every week. Every week, students had to take a test and they were expected to achieve a certain proficiency level before they were allowed to take the next test; otherwise they were required to repeat the test until the required proficiency level was achieved.

\section{Lectures}

Since lectures would defeat the purpose of the constructivist nature of the PBL teaching approach, in the remaining six weeks of the course, the whole three hours of weekly class time was allocated to student learning with the lecturer/tutor acting as a facilitator for the learning process. Students were supposed to hold their meetings during the first hour and then use the remaining two hours for searching information relevant to the problem to be solved. The role of the teacher during the second part of the course was to guide students through the process of answering PBL questions and to not provide any answers. 


\section{Devising a Suitable PBL Problem}

In the PBL teaching approach, problems are vehicles by which students obtain knowledge in a variety of disciplines. Good problems promote the acquisition of appropriate skills and content knowledge and combine topics from the course with what students see and do every day. When creating PBL problems (or selecting from existing PBL materials), it should be ensured that they are based on the curriculum and are grounded in student experience. The problems should promote the acquisition of knowledge and the development of skills and accommodate a variety of teaching and learning strategies and style. Additionally, the problem should be ill-structured so that students can explore its complexity and understand that there could be more than one solution to the problem. Some essential characteristics of a good PBL problem are (Duch, 2001): (a) it should engage students' interest and motivate and connect them to the real world; (b) students should make decisions/judgements based on facts, information, reasoning, etc; (c) it should be complex enough to require cooperation as a group; divide and conquer strategies are not effective; (d) initial questions are open-ended and group discussion is encouraged; and (e) course content objectives are embedded in the problem and situation.

With these characteristics in mind, the problem devised to drive the whole of the second part of the course was:

Using a group of 4 or 5 students, write a 5000-word academic paper and deliver a 20-minute presentation to answer the following: A Fuzzy Expert System (FES) is an Expert System that uses a collection of fuzzy membership functions and rules instead of Boolean logic to reason about data. (1) Explain in detail what an FES is? (2) How would you use an FES to forecast: either (a) tomorrow's temperature in Melbourne or (b) the Australian Stock Exchange "All Ords Price Index" for next month or (c) next month's retail price of unleaded petrol in Melbourne?

\section{Evaluating Students}

The process of evaluation in PBL is more encompassing in its methods, procedures, and goals than the traditional tests and papers which show what students have learned (Delisle, 1997). Evaluation is integrated throughout the process as the teacher observes the abilities of students during each step of the process. Throughout the PBL activities, the teacher watches students brainstorm possible solutions, review their prior knowledge, determine key questions, develop a research methodology to collect information, conduct the research, develop a solution, explain their reasoning, produce a final product, and present the product. The teacher evaluates each student, both individually and as part of a group, throughout each stage of the PBL process. Several criteria were selected to assess students on the following skills: problem solving, team-work, and independent learning. The forms and questions used for evaluation purposes were adapted from Delisle (1997) and evaluation was performed for summative (grading) as well as formative (improvement) purposes.

The deliverables of the group assignment (an academic paper and a presentation) were assessed using traditional methods and were delivered in two stages. In the first stage (after three weeks), a preliminary answer to question 1 was due as a group presentation of 10 minutes. Students were required to integrate any feedback obtained at the presentation to improve their answer for the final presentation and academic paper. In the second stage (at the end of the semester), students had to choice of answering either part $\mathrm{a}, \mathrm{b}$ or $\mathrm{c}$ of question 2. Part a was designed to appeal to students with Science (including Computer Science) background, part $b$ for students with finance background and part $\mathrm{c}$ for students with business background. At the end of this stage, a group presentation of 20 minutes and the academic paper were due.

Finally, at the end of the PBL phase of the course, immediately after the group presentation, students were asked to reflect on their performance in that phase of the course. They were asked to 
assess themselves, their team mates, their group and their teacher. Again, the forms and questions used for evaluation purposes were adapted from Delisle (1997).

\section{Implementation}

The course was delivered in semester 1,2006, and after some initial minor fluctuations, course enrollments stabilized at 34 students. The first part of the course went well as there were no withdrawals because of students' apprehension about programming and there were no problems with online tests.

\section{Induction to PBL}

In the first session of the second part of the course, the PBL process was explained to students as it can be frustrating and disturbing for new students. In PBL, students are encouraged to be active rather than passive and co-operate rather than compete. It is advisable to develop an induction program to prepare students for some potentially distressing aspects of PBL that might be caused by a change in learning approach (Centre for Learning and Professional Development, 2006) and maximize the learning opportunities provided by PBL.

Students were invited to form groups of maximum of five students as this size was judged to be suitable for the complexity of the work involved and also, as a general rule, four to five students work well together. After groups were formed, students were engaged in two team-building exercises, namely tower building and team charter (Federman Stein \& Hurd, 2000). The main aims of these exercises were to: (a) open communication channels within the group, (b) facilitate the sharing of information and expectations between group members and (c) encourage the social bonding process. Students were also provided with notes extracted from McGourty \& De Meuse (2001) on the following topics: (a) how to resolve group conflict; (b) how to conduct effective team meetings; and (c) becoming an effective team member.

Finally, at the end of the first session, students were presented with the problem to solve and asked to hold their first meeting. Groups were provided with a form to record the learning issues identified (what they do not know and need to find out), the learning resources to be utilized, the persons responsible for these actions and their action plan. Students then broke off for their independent self-directed learning activities.

The following week students reconvened in class, shared and reviewed the information they collected over the week. Groups again used the form to record the learning issues identified, the learning resources to be utilized, the persons responsible for these actions and their action plan. At the end of the session, students broke off once again for their independent self-directed learning activities. This cycle continued until the solution to the problem was found.

\section{Class Attendance}

One interesting thing happened during the implementation of the course. At RMIT University, class attendance is not mandatory and is generally low. In the first part of the course, class attendance fluctuated, however in the second part of the course where PBL activities were conducted, on average $92-93 \%$ of the class was present most of the time. The weekly class attendance is shown in Figure 2. 


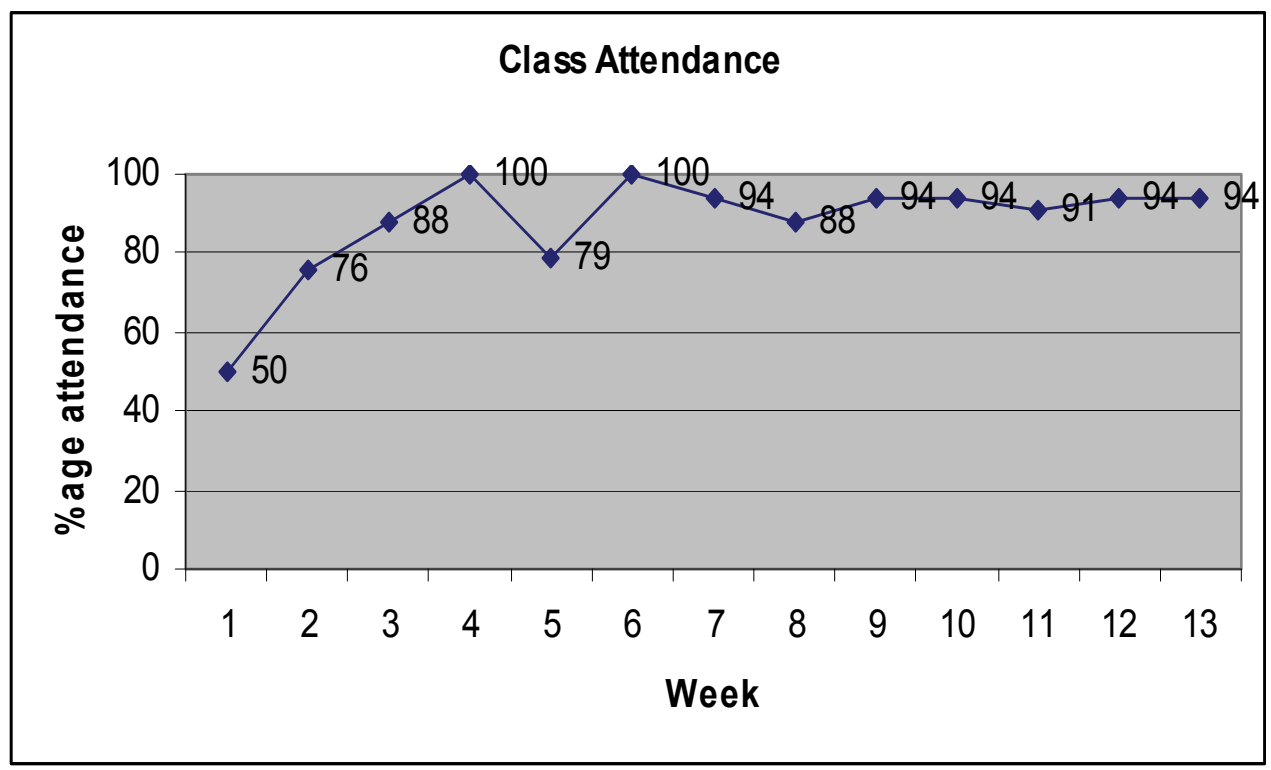

Figure 2: Class attendance

The evaluation of the PBL approach was performed as part of the end-of-semester course evaluation survey that is regularly conducted for the aim of improving the course. A customized paperbased survey questionnaire was devised for the purpose of obtaining: (a) demographic information; (b) information on the traditional approach used in the first half of the course; and (c) information on the PBL approach used in the second half of the course.

The questionnaire was administered immediately after the last presentation in week 13. In an attempt to obtain genuine responses, this was done while students were reflecting on their performance on the last part of the assignment and they responded anonymously. The response rate was very good as 32 out of the 34 students enrolled in the class responded.

\section{Results and Discussion}

The student cohort was predominantly full-time (32 students), international students (30), male (25) and of an average age of 25 years. This is quite normal as the course was conducted during the day from 9.30 am to $12.30 \mathrm{pm}$ and was hence attended by mostly full time students who are in general international students and aged around 25 years.

\section{Time Spent Studying}

On average, students said that they spent 11 hours per week studying on their own for this course while they spent 13 hours per week on casual work. Casual work is a term that is used to describe a range of employment situations where the work is not regular or permanent in areas such as: retail, hospitality, telemarketing, clerical, childminding, gardening, cleaning, and degreerelated and on-campus work. Many students do this type of work to support themselves financially.

The self-study hours seem to be overstated while the casual work hours understated as students are expected to spend a maximum of 7 hours for self-study and international students in Australia are allowed to perform up to 20 hours of casual work while on a student visa. A major problem with international students in Australia is that they are often on tight budgets and they are engaged in unreasonable number of hours of casual work and this has a negative impact on their studies. 


\section{Evaluation of the Traditional Instructivist Teaching Approach}

In the first part of the course, where the traditional instructivist approach was used for delivery, students rated their comprehension of the course materials and the business rules coded in JESS as very good (4 on a 5-point Likert scale). $98 \%$ of the students said that they participated very much (4 and above on a 5-point Likert scale) in their group assignment and on average students did not find it hard ( 2 on a 5-point Likert scale) to work in group. The reasons given by those who found it hard to work in group (25\%) were: (a) they cannot find a suitable time to meet because of different class time table and the need to work, (b) communication barrier (in case of multicultural groups), (c) group members not taking their responsibility, etc. Because of the difficulties of finding a time to meet, one student suggested to reduce the size of groups to three members as three students are more likely to find a suitable time than five.

Students found the online hurdle tests to be useful because it forced them to read the lecture notes and the prescribed textbook. One student admitted getting help from his friends over the phone; another one mentioned that she just flipped over the pages of the textbook to search for the answers while another one thought that forcing him to read the textbook was good for improving his English reading skills. A slight majority (53\%) of the students would have preferred the tests to be graded.

\section{Evaluation of the PBL Teaching Approach}

In the second part of the course where the PBL approach was used, $60 \%$ of students mentioned that they had never been engaged in PBL before and 47\% mentioned that they were not comfortable with the fact that there were no formal lectures in the second part of the course.

\section{Desirability of formal lectures}

The reasons advanced by students who favoured the idea of no formal lectures are: (a) they have more time to discuss assignments and ask questions to the lecturer; (b) they do not have to spend more time outside class to discuss the same things again; (c) it is easier to do group work as all members are present in class; (d) they interact more with team members as well as with the whole class; (e) they are given more flexibility; and (f) they like exploratory learning as they obtained proper guidance. One student mentioned that the absence of formal lectures "... gave us more time to focus on the project and helped and enabled us to learn more than just the subject related matters".

Students who wanted formal lectures mentioned the following reasons: (a) they need lectures to clarify doubts they might have; (b) they need lectures to have a better understanding of the course; (c) they are not sure whether what they learned is right or wrong; and (d) not having lectures is a waste of time. One student thought that "It is essential that students be provided sufficient background to the requirement of the assignment as it will become heavy workload on us if we have to learn everything ourselves".

\section{Evaluation of PBL process}

An overwhelming majority of students (88\%) stated that they enjoyed the PBL process, the reasons being: (a) it helped them learn together and solve problems related to the course; (b) it is an interesting way of learning provided the team works well together; (c) this learning approach provides the highest standard of self-control and planning; (d) it is good for improving research skills; (e) they really learned something, deeper what was learned in the bachelor's degree; (f) it really helped them to understand the assignment; and $(\mathrm{g})$ they learned more than in the first part of the course. 
One student said "Great team. Everybody contributed. Not always the case at RMIT" and another one commented that "It was quite interesting and enabled us to learn more than the first lectures. It is for sure we learnt and implemented in our project. So our ideas and thinking are improved".

A few students who did not enjoy the PBL process mentioned the following reasons: (a) too hard to find useful information; (b) too difficult; and (c) too time consuming.

\section{Teaching and learning preferences}

When asked about their teaching and learning preference, $53 \%$ of the class mentioned they preferred the traditional method, and $6 \%$ were unsure.

The reasons for preferring the traditional method were: (a) students learn more with lectures; (b) PBL seems to be no more than discussion; (c) too hard for students to find information by themselves; (d) easier for students to understand what they are studying; (e) students suffer less pressures and stresses; (f) lectures provide the background to search for further information; (g) students are familiar with the conventional method; and (h) they find it easier.

The reasons for preferring PBL were: (a) it is more interactive and goal-based; (b) students have full control of the time schedule to obtain the best possible outcome; (c) they can go deep into the research; (d) improved learning through interaction and exchange of views between students rather than listening to the lecturer; (e) greater learning effect when applying knowledge to practical problems; (f) students are free to focus on their preferred topics; (g) they work on real workplace problems, etc. One student commented "this one is really very effective and helped us to learn more. Teaching and learning method is very interactive and effective, where we can give our best and learn efficiently"

\section{Perceived pros and cons of PBL}

The aspects of PBL students liked were: (a) self-learning; (b) understanding on their own and applying that understanding; (c) pooling of knowledge after their individual research; (d) developing the habit to read papers and the work of others on topics of interest; (e) self-control of the study schedule; (f) helping to improve communication skills and independent research; (g) it was just like work as the problem was realistic; (h) teamwork and brainstorming; (i) using their own ways to solve a problem; and (k) interactive method which makes students learn more. One student remarked that "It was different. I had never experienced something like that and it was enjoyable".

Students said they disliked PBL for the following reasons: (a) they cannot resolve any confusion they may have immediately; (b) they sometimes found it difficult to understand a concept even after a lot of brainstorming with team members; (c) it is time consuming; (d) since there are no lectures they cannot judge whether the information collected is right or wrong; (e) there is too much non-structure; (e) it does not seem to be as efficient as the conventional teaching method; (g) there are no guidelines or specific goals for each week; (h) they have to find a lot of information by themselves; (i) it's hard to find useful materials; and (j) high levels of uncertainty and low probability of finding the exact solution. One student said "There is nothing wrong with PBL; it is just that I prefer the conventional method of teaching and learning".

\section{Evaluation of the Course}

Given the high levels of class attendance and involvement in class activities, the enthusiasm observed by the lecturer and tutor, and the favorable overall comments on the course (as shown in Table 1), it can be concluded that the course was popular with students. 
Table 1: Overall comments on the course

\begin{tabular}{|l|}
$\begin{array}{l}\text { "The course is really amazing! It is quite interesting and has made me learn a lot. I believe that } \\
\text { this course should be available to all students and not made an elective which would be difficult } \\
\text { to take up due to the program structure" }\end{array}$ \\
\hline "Interesting, it was tough but fun and gave me what I paid for" \\
\hline "Very interesting. Increased my interest in KBS and FES" \\
\hline $\begin{array}{l}\text { "A good course to tell me information about Intelligent Systems and to try the PBL teaching me- } \\
\text { thod improves my communication skills and research skills" }\end{array}$ \\
\hline "Overall, I found this course interesting except that it's time consuming" \\
\hline "Good. The different method of teaching and different methods of doing the assignments" \\
\hline "It's deeper than what I did in my bachelor degree. It's indeed useful for my future" \\
\hline $\begin{array}{l}\text { "Excellent, it enabled me to get innovative ideas and helped me learn more and was very interest- } \\
\text { ing" }\end{array}$ \\
\hline "Interesting in-depth knowledge can be obtained by spending adequate time. Overall very good" \\
\hline "It's still really interesting. I would prefer to do it in final semester" \\
\hline $\begin{array}{l}\text { "It's a very interesting and useful course. I enjoyed it", "Interesting style of teaching. Right load } \\
\text { of the assessments" }\end{array}$ \\
\hline "A different and interesting subject but too much experimentation tried" \\
\hline "First part was good, but second part was puzzling. Overall average" \\
"It is just OK, but a bit boring become I come from non-IT background" \\
\hline
\end{tabular}

As previously mentioned in the section entitled "Evaluating Students," there was continuous assessment of the problem solving, teamwork, and independent learning skills of students, as observed by their tutor in class. Hence, the grading system used took into consideration the quality of the product (assignment deliverables) as well as the process used to arrive at the solution to the problem. At the conclusion of the course, the distribution of grades was $0 \%(0)$ of students with high distinction, 32\% (11) with distinction, 53\% (18) with credit, $12 \%$ (4) with pass, and 3\% (1) with fail. Eighty-five percent of students achieving a grade of credit and above is evidence that the course was effective in facilitating students' learning experience.

Although $88 \%$ of students enjoyed the PBL experience, their preferences leaned towards a combined traditional and PBL approach. Their main suggestion for improving the course was to combine the PBL approach with the traditional method through the introduction of a small teaching part e.g. half-hour lectures and providing basic materials. Students also wanted more frequent feedback so they know whether they are in the right direction.

\section{Conclusion}

In an attempt to promote deeper learning in an Intelligent Systems course, a PBL approach was used to teach part of the course and data was collected using a questionnaire survey to evaluate the effectiveness of the approach. Generally, data collected from students through a questionnaire survey should be interpreted with caution as some responses may not be genuine. For example, some students tend to understate the number of hours they spend on casual work and overstate the 
number of hours spent studying. However, in this study, the main aim was not to make statistical generalizations, but rather to gauge the applicability and usefulness of the PBL approach in an AI-related course. Study results indicate that the PBL approach can be used for teaching the Intelligent Systems course, and most likely other ICT-related courses. PBL can also be used to teach non-Western students, despite the common belief that PBL is suitable for teaching Westerners only. Ninety-four percent of the class studied here consisted of international students, primarily from Asia and Southeast Asia.

The study also indicated that a pure PBL approach is not appropriate because of the anxiety caused to students when no background material and immediate feedback are available. In the future, the course will be redesigned by combining aspects of the traditional approach with the PBL approach. Students will be required to solve smaller sized PBL problems rather than a large problem with several milestones. Smaller problems that can be solved over a week or two combined with short lectures covering background information and discussion of suggested solutions will be experimented in future versions of the course.

\section{References}

Barrows, H. S. (2000). Problem-based learning applied to medical education. Springfield, Illinois: Southern Illinois University School of Medicine.

Barrows, H. S., \& Tamblyn, R. H. (1980). Problem-based learning: An approach to medical education. New York, NY: Springer Publishing.

Bransford, J. D., Sherwood, R. D., Hasselberg, T. S., Kinzer, C. K., \& Williams, S. M. (1990). Anchored instruction: Why we need it and how technology can help. In D. Nix \& R. Spiro (Eds.), Cognition, education and multimedia: Exploring ideas in high technology. Hillsdale, NJ: Erlbaum.

Bruer, J. T. (1993). Schools for thought: A science of learning in the classroom. Cambridge, MA: MIT Press.

Brunning, R. H., Schraw, G. J., \& Ronning, R. R. (1995). Cognitive psychology and instruction. Englewood Cliffs, NJ: Prentice Hall.

Centre for Learning and Professional Development. (2006). Leap into problem-based learning. Retrieved 24 February, 2006, from http://www.adelaide.edu.au/clpd/materia/leap/leapinto/ProblemBasedLearning.pdf

Clement, J. (1983). A conceptual model discussed by Galileo and used intuitively by physics students. In D. Gentner \& A. L. Stevens (Eds.), Mental models. Hillsdale, NJ: Erlbaum.

Collins, A., Brown, J. S., \& Newman, S. (1989). Cognitive apprenticeship: Teaching crafts of reading, writing and mathematics. In L. B. Resnick (Ed.), Knowing, learning, and instruction: Essays in the honor of Robert Glaser. Hillsdale, NJ: Erlbaum.

Delisle, R. (1997). Use problem-based learning in the classroom. Alexandria, Virginia: Association for Supervision and Curriculum Development.

Dewey, J. (1944). Democracy and education. New York: The Free Press.

Duch, B. J. (2001). The power of problem-based learning. In B. J. Duch, S. E. Groh \& D. E. Allen (Eds.), The power of problem-based learning (pp. 47-53). Sterling, Virginia: Stylus Publishing.

Federman Stein, R., \& Hurd, S. (2000). Using student teams in the classroom: A faculty guide. Boston, Massachusetts: Anker Publishing Company.

Gijselaers, W. H. (1996). Connecting problem-based practices with educational theory. In L. Wilkerson \& W. H. Gijselaers (Eds.), Bringing problem-based learning to higher education: Theory and practice. San Francisco: Josey-Bass Publishers. 
Glaser, R. (1991). The maturing of the relationship between the science of learning and cognition and educational practice. Learning and Instruction, 1, 129-144.

McGourty, J., \& De Meuse, K. P. (2001). The team developer: An assessment and skill building program. New York: John Wiley.

Savin-Baden, M. (2000). Problem-based learning in higher education: Untold stories. Buckingham, UK: Open University Press.

Schmidt, H. G. (1993). Foundations of problem-based learning: Some explanatory notes. Medical Education, 27, 422-432.

Wee Keng Neo, L. (2004). Jump start authentic problem-based learning. Jurong, Singapore: Prentice Hall.

\section{Biography}

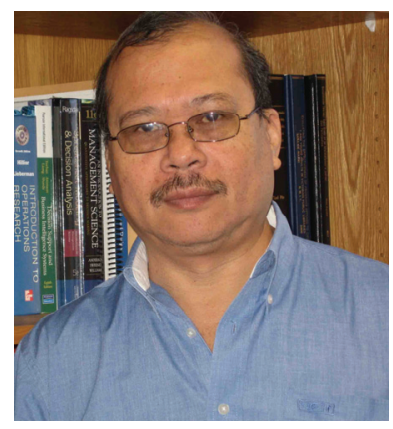

France Cheong is a senior lecturer in the School of Business Information Technology, Royal Melbourne Institute of Technology (RMIT) University. He holds a Bachelor of Business (Computing), Master of Computer Science, Master of Education (Teaching) and a PhD (Computer Systems Engineering). His research interests are in the area of complex systems modelling and simulation using a range of intelligent systems and other techniques. 